\title{
Do giro linguístico ao giro ontológico na atividade epistemológica em Educação Física
}

\author{
Felipe Quintão Almeida* \\ Alexandre Fernandez Vaz **
}

\begin{abstract}
Resumo: apresenta a interpretação que parte da tradição marxista na educação física brasileira realiza da virada e/ou do giro linguístico no âmbito de sua atividade epistemológica. Descreve a reação sugerida por aquela tradição (inflexão ontológica) com o objetivo de se contrapor àquela presença. Conclui com algumas implicações da reação proposta para a atividade epistemológica em educação física.
\end{abstract}

Palavras-chave: Conhecimento. Linguagem. Virada Linguística. Ontologia. Educação Física.

\section{INTRODUÇÃO}

O debate que envolve as discussões epistemológicas em educação física é bastante recente. Esse atraso, de alguma maneira, pode ser explicado pelo fato de ela, durante muito tempo, ter sido considerada, conforme já há dez anos apontara Bracht (1999), muito mais uma área de aplicação do que de produção de conhecimento. Costuma-se atribuir à década de 1980 e a seu movimento renovador as possibilidades de a educação física se pensar como componente curricular que produz seus próprios conhecimentos, relativizando, assim, seu colonialismo epistemológico (GAMBOA, 1995) em relação às ciências-mãe, como a físiologia, a biomecânica, a psicologia, etc. Desde então, é possível identificar iniciativas diversas com vistas a entender o conhecimento produzido pela área.

\footnotetext{
*Doutor em Educação. Professor Adjunto do Centro de Educação Física e Desportos da Universidade Federal do Espírito Santo (CEFD/UFES). Laboratório de Estudos em Educação Física (LESEF/CEFD/UFES). Núcleo de Estudos e Pesquisas Educação e Sociedade Contemporânea (CED/UFSC). Florianópolis, SC, Brasil. E-mail: fqalmeida@hotmail.com

*Doutor em Ciências Humanas e Sociais. Núcleo de Estudos e Pesquisas Educação e Sociedade Contemporânea, UFSC; Pesquisador CNPq. Florianópolis, SC, Brasil. E-mail: alexfvaz@uol.com.br
} 
Em um primeiro momento, como sobejamente conhecido, temos aqueles estudos cuja preocupação recaía na identificação das principais áreas e subáreas nas quais a pesquisa era produzida. Após isso, podemos identificar aqueles estudos cuja intenção era descrever as matrizes teóricas ou as concepções de ciência que embalavam as pesquisas da área. Uma das investigações mais citadas, nessa direção, é "Mestrados em educação física no Brasil: pesquisando suas pesquisas", de Rossana Valéria de Souza e Silva (1990). Nesse trabalho, ela popularizou o que se tornaria uma famosa classificação epistemológica: empírico-analítica, fenomenológico-hermenêutica e crítico-dialética, que ainda hoje orienta muitos esforços na área. São essas investigações que marcam o início da discussão propriamente epistemológica no campo. A pergunta, a partir de então, não se dava apenas sobre o tipo de ciência presente na educação física, mas questionava-se se a própria educação física poderia ser uma ciência ou uma disciplina científica. É nesse momento, que atravessou a década de 1990, que o debate epistemológico em educação física viveu seus "dias de glória". Inúmeros autores se destacaram em suas posições sobre o (não)lugar da educação física no quadro geral das ciências.

Embora tudo isso esteja muito bem documentado, nunca é demais lembrar que a celeuma instalada "originou" duas vertentes (BETTI, 1996; LIMA, 1999) para a compreensão do problema: a vertente científica e a vertente pedagógica. A primeira delas incluía nomes como Go Tani, Jefferson Canfield, Adroaldo Gaya, Manoel Sérgio e buscava atualizar uma expectativa presente na década de 1970, ou seja, conferir cientificidade cada vez maior à educação física. O motor dessa pretensão, como sugeriu Lovisolo (1995), é a valorização da ciência. Nos casos mais extremos, chegou-se mesmo a defender a transformação da própria educação física em ciência (ciência da motricidade humana) ou, então, a criação de uma nova ciência (a ciência do movimento humano, a cinesiologia). A despeito de todas as diferenças entre os membros dessa matriz, suas proposições estabeleciam uma relação hierárquica de dependência com a educação física. Mais uma vez, a especificidade da disciplina é definida na medida em que aplicamos o conhecimento 
produzido por outros, os cientistas. A vertente pedagógica, composta por nomes como Valter Bracht, Hugo Lovisolo, Elenor Kunz, Mauro Betti, Silvio Gamboa, Kolyniak Filho, reforçava a necessidade de voltar o conhecimento produzido na área, em sua multidisciplinaridade, para as necessidades oriundas da prática ou da intenção pedagógica. A despeito de todas as divergências existentes entre eles, todos pareciam convergir para dois pontos: em primeiro lugar, tomaram a educação física como "ponto de partida e de chegada" de suas reflexões, comprometendo-se com elas. Em segundo lugar, é a cultura a referência norteadora da educação física como prática pedagógica. Não significa, claro, que os autores dessa vertente não se interessassem pela ciência, mas, com eles, a relação da educação física com ela se daria de uma maneira mais horizontal (não vertical, como na vertente científica). A educação física, portanto, não somente aplicaria conhecimento, mas também o produziria.

Se o debate entre as vertentes científicas e pedagógicas dominou a discussão epistemológica ao longo da década de 90, os anos 2000 viram essa discussão perder força com a presença de novos temas bem como com a entrada de novos interlocutores, dentre os quais podemos destacar os nomes de Terezinha Petrúcia da Nóbrega, Vidalcir Ortigara, Astrid Ávila, Paulo E. Fensterseifer, Homero Luis de Alves Lima, Luiz Carlos Rigo, entre outros. No momento atual, em que nossa "atividade epistemológica" (FENSTERSEIFER, 2006) é marcada por um pluralismo teórico e político, os responsáveis pela condução do Grupo de Trabalho Temático (GTT) Epistemologia, do Colégio Brasileiro de Ciências do Esporte (CBCE), têm "dado" o tom do debate ao propor uma agenda para a discussão. Se levarmos em conta os temas centrais dos dois últimos "Colóquios de epistemologia da educação física", organizados por aquele GTT, teríamos os seguintes eixos norteadores:

a) giros epistemológicos na educação física/ciências do esporte;

b) epistemologias e teorias do conhecimento na pesquisa em educação e educação física: as reações aos pós-modernismos. 
Trata-se de dois temas interligados, afinal, costuma-se associar o pós-modernismo aos giros (linguístico e/ou hermenêutico e pragmático) e vice-versa. Neste artigo, tratamos de uma contraposição à presença dos giros em educação física ${ }^{1}$, aquela que responde pelo nome de reação ontológica. Para desenvolver este objetivo, inicialmente apresentamos a descrição que os advogados dessa reação operam dos giros em educação física, expondo, inclusive, a solução sugerida para enfrentá-los; após isso, finalizamos discutindo algumas implicações da reação proposta para nossa atividade epistemológica, como oportunidade para expressar nossas próprias posições.

\section{Os GIROS OU VIRADAS NA EdUCAÇÃo FísICA: UMA ANÁLISE À LUZ DA REAÇÃO ONTOLÓGICA}

Iniciemos a descrição sugerida ${ }^{2}$ tomando como base aquilo que está no centro mesmo das viradas em suas diversas vertentes, ou seja, a relação entre a linguagem e o mundo ou, posto na linguagem filosófica, a crítica ao representacionismo que animou a filosofia moderna. Talvez a metáfora que melhor expresse o que vem a ser o representacionismo seja aquela cunhada pelo filósofo norteamericano Richard Rorty, segundo o qual a mente funciona como um espelho do que acontece na natureza. Em tais circunstâncias, a preocupação central da filosofia, para citar o próprio Rorty (1994, p. 20), "[...] é ser uma teoria geral da representação, uma teoria que dividirá a cultura nas áreas que representem bem a realidade, aquelas que não representam tão bem e aquelas que não a representam de modo algum (apesar da pretensão de fazê-lo)". Nesse sentido, o alvo central de sua crítica é a concepção "correspondentista" da verdade, segundo a qual o pensamento deve refletir ou representar,

\footnotetext{
${ }^{1}$ Por consequência, à presença dos "pós-modernismos" no campo.

${ }^{2}$ É preciso dizer que essa descrição é tributária de uma contraposição aos giros que tem vez no campo educacional mais amplo. Trata-se de uma reação àquilo que a professora Maria Célia Marcondes de Moraes (2004), inspirada na teórica marxista Ellen Wood, chamou de agenda pósmoderna, na medida em que se observa que, no cerne dessa agenda, estão, conforme a própria Wood (1999), a linguagem, a cultura e o discurso (portanto, as viradas ou giros em suas variadas vertentes: pós-estruturalismo, neopragmatismo, hermenêutica, filosofia pós-analítica, estudos culturais, etc.).
} 
fielmente, a realidade como ela de fato é, em sua objetividade. Vale ressaltar que o representacionismo é o núcleo hard do empreendimento epistemológico moderno, cuja tarefa é zelar para que nossas crenças representem a realidade com exatidão, em sua verdade objetiva.

Alguns autores que participam deste debate na educação física, tais como Gamboa, Ávila e Ortigara, interpretam essa crítica ao representacionismo (e ao realismo que ele pressupõe) como um déficit na tarefa de se obter um conhecimento objetivo do mundo. Objetivo, é preciso ressaltar, no sentido de "chegar ao real" em sua materialidade, como ele realmente é e pode ser desvelado pela filosofia, pela ciência, pela arte etc. Como conseqüência do vácuo aberto por este "colapso" da objetividade, solapa-se a possibilidade de capturar a verdadeira essência da realidade, pois isso agora depende, após os giros, das descrições linguísticas que dão forma à nossa cultura.

No debate filosófico mais amplo, a dependência da linguagem na definição da realidade é muitas vezes caracterizada pela expressão antirrealismo. Não é diferente na educação física. Ávila (2008), discutindo a presença desses antirrealismos (leia-se o pós-estruturalismo, o neopragmatismo, o multiculturalismo etc.) na área, chega mesmo a colocar "lado a lado" o antirrealismo e o idealismo. Segundo ela e Ortigara (2007b, p. 14), o antigo debate filosófico entre o realismo e o idealismo

[...] passou a polarizar em torno dos que consideram que o real existe independentemente de o conhecermos ou não, e justamente por isso, é cognoscível, e os que consideram o real incognoscível e até mesmo inexistente, ou que só ganha existência como produto do conhecimento ou da cultura.

Contra a "morte do real" (portanto, da Objetividade) e sua dissolução nos jogos de linguagem, Gamboa, Ávila e Ortigara sugerem a premência de se restaurar a realidade como dimensão insuprimível da relação entre o sujeito que conhece e o objeto conhecido. E os três vão encontrar na ontologia a solução para essa necessidade, 
pois ela, ao tratar exatamente daquilo que é (supostamente) negligenciado por perspectivas julgadas antirrealistas, interessa-se pela tessitura do real, implicando no reconhecimento do ser por-si (na linguagem kantiana, do em-si), daquilo que existe independente de ser pensado e conhecido. É nesse contexto que Gamboa (2007) vai propor uma re-virada, inflexão ou reação ontológica aos giros lingüísticos em educação física. De acordo com ele (2007, p. 1), essa reação

[...] vem das teorias do conhecimento que superando os conceitos originais do 'mentalismo' (a representação dos objetos ou coisas na mente) reafirmam a necessidade de considerar a realidade (ontos) independente da consciência e da linguagem. O discurso e a linguagem deverão se referir a alguma realidade (objeto) ou referente empírico, construído social e historicamente, ou mesmo virtual, mas independente do sujeito, da sua percepção, da consciência e das palavras utilizadas para se referir a ele.

Ou, nas palavras de Ávila (2008, p. 1):

[...] é preciso compreender que para conhecer é necessário primeiro que os objetos do conhecimento existam e, segundo, reconhecer a independência (ao menos relativa, no caso dos fenômenos sociais) do objeto em relação às formas de consciência, o que significa dizer, que ele existe independentemente do conhecimento que possuímos dele.

Nesse sentido, como advogou a própria Ávila (2008), o que se coloca é a urgência de se defender o realismo (ontológico) ante qualquer perspectiva antirrealista que se faça presente hoje na educação física. É preciso, como expressou Ortigara (2002), Ortigara et al. (2009), trazer para a educação física o que até então estaria faltando: a ontologia. São alguns desdobramentos desse imperativo na área:

A prioridade ontológica do real significa reconhecêlo como uma existência independente de como o pensamos ou o conhecemos. O ser social tem sua gênese em sua ação ativa de intercâmbio orgânico 
com a natureza, assegurando sua produção e reprodução. Cria sua própria condição de humanidade mediante o trabalho. Esse processo ocorre independentemente de termos ou não consciência ou conhecimento a seu respeito (ÁVILA; ORTIGARA, 2005 , p. 2-3).

O conhecimento, inclusive o científico, precisa ser discutido e refletido enquanto um elemento que constitui o ser social e que tem características muito específicas na forma social capital. Desta maneira, as questões levantadas neste texto podem contribuir na reflexão sobre a pesquisa e a intervenção em Educação Física ressaltando a importância de uma abordagem ontológica para pensar o ser social, o conhecimento e a ciência. Isso poderá permitir que questionemos o conjunto de crenças que são criadas em nossa área (ÁVILA; MULLER; ORTIGARA, 2007, p. 7-8).

Reafirmamos, assim, a prioridade ontológica do real, o fato de que possui uma existência independente de como o pensamos ou o conhecemos. O ser social efetiva-se mediante sua ação ativa de intervenção sobre a natureza, assegurando sua existência, criando sua própria condição da humanidade. É algo que ocorre independentemente de termos consciência ou conhecimento deste processo (ORTIGARA, 2002, p. 50).

Buscamos desenvolver um contraponto à noção de conhecimento neopragmático [...] apresentando alguns pressupostos centrais da ontologia que nos serve como referência, sustentando, assim, a possibilidade do espelhamento do real. Medeiros (2004, p. 1) [...] afirma que '[...] toda e qualquer prática humana (inclusive a ciência) pressupõe uma imagem de mundo (ontologia) e que a negação da ontologia não apenas torna tais práticas incompreensíveis, como efetivamente bloqueia a crítica e favorece o conservadorismo político' (ÁVILA; ORTIGARA, 2007a, p. 301). 
É nesse contexto que o consagrado filósofo húngaro Georg Lukács e o filósofo da ciência Roy Bhaskar são utilizados em favor da reação ontológica no debate epistemológico da área ${ }^{3}$. Com Lukács, observa-se, em linhas gerais ${ }^{4}$, que:

a) as viradas em curso prolongam uma tendência já presente nos primeiros irracionalistas, ou seja, a repulsa à realidade objetiva, uma negação à cognoscibilidade do real, à verdade como correspondência etc.;

b) o mesmo equívoco praticado por idealistas subjetivos e (neo)positivistas, no tempo em que Lukács escrevia, reproduzir-seia nas mesmas condições dos giros: a unilateralidade da orientação epistemológica ou gnosiológica à efetividade da coisa em si, o que faz da ontologia um apêndice da epistemologia. Em tais condições, os giros linguísticos são concebidos como a mais nova orientação idealista da filosofia contemporânea, solapando a autoridade da ontologia como fundamento à efetividade do conhecer;

c) as tendências antirrealistas em educação física nada mais, nada menos, respondem de modo conservador às reestruturações do capitalismo contemporâneo, uma conclusão semelhante à que Lukács (1976) tinha chegado em relação às filosofias idealistas e (neo)positivistas.

Em referência a Bhaskar, aufere-se que ${ }^{5}$ :

a) com o intuito de se contrapor aos giros, assumem a tese de Bhaskar segundo a qual os objetos do conhecimento, além de sua dimensão transitiva, ou seja, aquilo que é fruto da linguagem praticada por uma comunidade de justificação, possui também uma dimensão intransitiva, independente dos jogos de linguagem que a nomeiam. Essa dupla dimensão serve para se contrapor à ideia de que a própria intransitividade dos objetos do conhecer seja transitiva, isto é, fruto da linguagem (BHASKAR, 1975);

${ }^{3}$ Conferir os trabalhos de Gamboa, Ávila e Ortigara mencionados neste artigo.

${ }^{4}$ Trata-se, certamente, de uma simplificação. Seria preciso mais espaço para discutir essas conclusões em toda a sua extensão. Eles dão conta, contudo, dos nossos objetivos neste artigo.

${ }^{5}$ Ver comentário da nota anterior.

Movimento, Porto Alegre, v. 16, n. 03 p. 11-29, julho/setembro de 2010. 
b) comete-se falácia epistêmica toda vez que se analisa as proposições sobre o ser em termos de proposições sobre o conhecimento, isto é, questões ontológicas sempre podem ser transpostas em termos epistemológicos. Assim compreendido, o que se defende é a necessidade de o conhecimento vir depois da existência (o conhecer procede ao ser ou a epistemologia procede à ontologia). Em outras palavras, primeiro a realidade, depois o conhecimento sobre ela;

c) essa falácia, por sua vez, encobre a geração de uma ontologia baseada na categoria da experiência (uma ontologia das impressões). Essa ontologia velada, supostamente atualizada/praticada pelas perspectivas que assumiram os giros, remonta ao realismo empírico, perspectiva que, conforme Bhaskar, estava na base tanto do empirismo clássico, como do idealismo transcendental e do positivismo lógico;

d) a interdição da ontologia, vale dizer, da realidade, não passaria de um embuste, pois o que acontece é que a ontologia é negada para, paradoxalmente, ser afirmada de maneira relativizada, contextualizada ou pulverizada nos mais diversos jogos de linguagem. Estaríamos, assim, no terreno de um relativismo ontológico ou de um "superidealismo subjetivo" (BHASKAR, 1986) em educação física ${ }^{6}$.

Recorrendo-se a Lukács e Bhaskar, portanto ${ }^{7}$, espera-se restituir centralidade a princípios para os quais os praticantes dos giros, também em educação física, são supostamente negligentes: a verdade, a objetividade e a realidade. Como corolário, esse movimento tem a expectativa de: retomar o fio condutor que leva à concordância entre sujeito e objeto, entre a imagem do mundo e o mundo ou entre a ciência e a realidade; retomar a senda que leva às verdades objetivas, no sentido de elas corresponderem (ou espelharem) às reais estruturas da realidade; em suma, salvar o paradigma da

\footnotetext{
${ }^{6}$ Não surpreende a associação feita entre idealismo e antirrealismo.

${ }^{7}$ É importante dizer que essa descoberta de Lukács e Bhaskar não é exclusividade da educação física, mas antes acontece e se desenvolve, inclusive com os autores dessa área, na Educação e demais campos. Consultar, a título de exemplo, Duayer (2006), Hostins (2006) e Della Fonte (2006).
} 
subjetividade (a relação entre sujeito-objeto) de sua dissolução nos jogos de linguagem (caracterizada que é por uma relação sujeitosujeito).

Tendo apresentado, até aqui, as razões e os porquês (ou, pelo menos, parte delas) de alguns autores em educação física serem peremptoriamente contrários aos giros, apontando, inclusive, a resposta que vão oferecer para se contrapor a eles, gostaríamos de deixar o restante do artigo para apontar algumas implicações dessa inflexão ontológica pretendida para nossa atividade epistemológica.

\section{INFLEXÃo ONTOLÓGICA NA EdUCAÇÃo FíSICA: IMPLICAÇÕES PARA A ATIVIDADE EPISTEMOLÓGICA}

Temos, inicialmente, uma questão terminológica, pois o que se coloca, no quadro exposto, não é somente o retorno da ontologia, mas a necessidade da reflexão ontológica como precedente à epistemológica (ÁVILA; ORTIGARA, 2007a). Somente assim se evitaria a falácia epistêmica e suas consequências. Nessas condições, ao invés de atividade epistemológica (FENSTERSEIFER, 2006), deveríamos talvez falar em atividade ontológica da educação física.

Em segundo lugar, e caso se aceite a precedência da ontologia à epistemologia, poderíamos abrir mão inclusive da ideia de atividade e falar mesmo em ontologia da educação física. Uma proposta desse tipo solaparia, segundo nossa descrição, os recentes avanços alcançados pelo campo em sua discussão de caráter epistemológico, na medida em que a noção de uma atividade conserva aquilo que a noção de ontologia, tal como defendida pelos autores que descrevemos, parecer dispensar, ou seja, nosso sendo, o caráter sempre provisório e processual, nos dizeres de Fensterseifer (2006), que acompanha o que está vivo, que se repõe sempre que novas discursividades se colocam no âmbito de nossa área. Na medida em que alcançamos o verdadeiro modo como o mundo é em si, sua ontologia, qual o sentido deste sendo? 
Em terceiro lugar, a virada ontológica pretendida substituiria a equação $\mathrm{V}=\mathrm{R}=\mathrm{C}$ (Verdade $=\mathrm{Razão}=$ Ciência) que, conforme Fensterseifer (2006) embalou a epistemologia moderna, por uma nova equação: Verdade $=$ Real $=$ Ontologia $(\mathrm{V}=\mathrm{R}=\mathrm{O})$, que não é menos representacionista do que a primeira. Ambas as equações refletem um modelo de investigação chamado desvelamento da realidade, próprio de toda tradição representacionista. As duas assumem a forma de uma descrição do objeto do conhecimento de modo a "transpor a brecha" entre o objeto e o sujeito conhecedor. Fica mais fácil "ler" essa pretensão, se levarmos em conta que a inflexão ontológica em curso, à semelhança de outras tradições representacionistas, trata a linguagem como um meio de expressão, de representação ou de espelhamento do real, vale dizer, de sua objetividade. Nisso, aliás, os argumentos ontológicos em nada diferem da epistemologia em sua tarefa de checar acuradamente o real.

A adoção dessa nova equação implicaria a retomada de questões que, já há algum tempo, temos evitado em nossa atividade epistemológica. Por exemplo, qual educação física seria "mais verdadeira", "mais científica" ou, então, qual proposta poderia resolver de uma vez por todas nossa crise de identidade? Qual das propostas pedagógicas é mais crítica ou está mais perto dos reais interesses humanos? O parâmetro para decidir sobre essas questões, claro, seria o afastamento ou a aproximação do real, pois somente nessas condições o conhecimento não se limitaria "[...] a expressar as aparências ou determinar formulações que abrangem somente o imediato do objeto, o que, a nosso ver, pode redundar numa visão distorcida do real ou apenas lacunar, portanto, retirando qualquer perspectiva de generalização" (ÁVILA; ORTIGARA, 2007a, p. 304).

De nossa parte, gostaríamos deixar de lado o tipo de vocabulário dualista que opõe aparência a realidade, pois pressuposto nesse tipo de oposição está a ideia de que a qualidade de uma teoria consiste em sua Objetividade, entendida como correspondência com a realidade. Aliás, essa é uma das características, segundo Ávila (2008), que qualifica uma teoria como emancipatória, pois, por se ter corretamente, ou pelo menos aproximadamente, capturado 
aspectos do real, permitirá escolhas mais efetivas, como também auxiliará a mais bem analisar as alternativas postas. Isso porque quanto mais profundo nosso mergulho teórico em frente a um recorte da realidade, na perspectiva de desvendar as relações que o constituem, maior a possibilidade de tornar essa realidade inteligível. Em outras palavras, quanto mais profunda e penetrante nossa compreensão de algo, mais afastados estamos de sua aparência e mais perto da realidade. Isso possibilitará, de acordo com Ortigara (2002) e Ortigara et al. (2009), pensar e projetar uma educação mais coerente com as verdadeiras condições de existência dos homens e mulheres que cotidianamente convivem nos espaços educativos. Nessas circunstâncias, caberia aos argumentos de caráter ontológico distinguir o verdadeiro do falso, o ideológico do não ideológico, o consciente do não consciente, o crítico do não crítico, todas essas noções que foram redescritas com o advento das viradas ou giros linguísticos na educação física.

Com a ajuda do filósofo Rorty (1999, 2006), sugerimos ver o afã realista presente na inflexão ontológica como a versão iluminista do ímpeto religioso de se curvar perante um poder não humano (desse modo, como uma herança do monoteísmo). Afinal, para aquele filósofo, a expressão "a realidade como ela é em si mesma" ou, como disse Lukács (1978), a realidade do real, é apenas outro dos subservientes nomes de deus, uma atualização da reivindicação dos sacerdotes de que eles estão "mais próximos" ao olho de deus do que a laicidade. Acreditar que a ontologia tem esse poder é o mesmo que acreditar na existência de algo que seja a realidade por trás das aparências, a única descrição verdadeira do que está acontecendo, o segredo final. Assim, apelar à ontologia não proporcionaria esse conforto metafísico, ou seja, a possibilidade de comensurabilidade universal em um vocabulário final? Não possibilitaria cumprir um desejo presente na filosofia de Lukács (1978, p. 22), ou seja, defender uma "[...] concepção que seja historicista sem cair no relativismo e que seja sistemática sem ser infiel à História". Parece que esse é o caso, pois, sem esse ponto arquimediano, sem uma ontologia com poderes redentores, parece que estaríamos sem o Fundamento para as tomadas de decisão no mundo falibilista em que vivemos. Em 
outros termos, a pretendida reação ontológica em educação física pode ser lida como expressão de uma inexorável busca por Critérios, Fundamentos para nossas práticas, um Vocabulário que nos livre de qualquer dúvida, incerteza e que, ao invés disso, aponte na direção certa (no sentido de Verdadeira) em meio a tantas sendas a escolher. Isso equivale a dizer que os defensores do giro ontológico são muito intolerantes à contingência e ambivalência da linguagem, procurando algum porto seguro, algum argumento final e definitivo que solape de uma vez por todas a dissonância cognitiva de um mundo que recusa um vocabulário ontológico geral que se mostre indiferente a cada comunidade de justificação (vale dizer, a cada linguagem em particular).

Em quarto lugar, a virada ontológica tem como consequência a (re)instauração de uma razão monológica (FENSTERSEIFER, 2001) no âmbito das atividades epistemológicas em educação física, na medida em que, ao refutar a linguagem e a intersubjetividade (razão comunicativa) dos processos de validação do conhecimento, reinstaura a relação entre um sujeito do conhecimento que reflete um objeto colocado na natureza, humana ou social. Concordamos com Fensterseifer (2009), quando este diz que o conhecimento (e a atividade epistemológica) não revela ou descobre uma realidade já posta, mas constitui aquilo que tomamos como real. Logo, nossa tarefa não se encerra na concordância entre verdade e realidade, tal como pressuposta pela reação ontológica em curso, mas começa justamente pela interrogação das verdades que se apresentam como o real para nós. Tarefa que só pode ser reconhecida como digna se aceitarmos que não temos acesso à coisa em si, e mais que isso, não temos nenhum instrumento que o possa produzir. Para citar Fensterseifer (2009) mais uma vez, um democrata não precisa lamentar essa situação, dado ser essa a condição da própria experiência pluralista da democracia. Se não, pensemos que tipo de relação com o outro terá alguém que dá por pressuposto já estar de posse da única verdade realmente verdadeira?

Em quinto lugar, e levando em conta a presença de Lukács e Bhaskar no embate epistemológico atual, os usos que deles foram 
feitos acabaram originando uma nova classificação epistemológica, que se junta à já classicamente conhecida entre nós, ou seja, a que opõe às pesquisas empírico-analíticas, as pesquisas fenomenológicohermenêuticas e crítico-dialéticas. Essa é, ao menos, a proposição de Ávila (2008) que, ao anunciar a insuficiência desse tipo de classificação, propõe outra em seu lugar, mais coerente, segundo ela, com o espírito do tempo que infesta a intelectualidade de nossos dias na educação física. A nova classificação ficaria assim:

a) empiristas;

b) idealistas;

c) paradigmas emergentes e antirrealistas (ambas, segundo a autora, irracionalistas);

d) realistas científicos ${ }^{8}$.

As três primeiras tendências, segundo a tese da autora, compartilham a mesma ontologia velada, ou seja, o realismo empírico (uma evidente influência de Bhaskar). Seria preciso, assim, contrapor a ele um realismo científico, "[...] a teoria que os objetos da investigação científica existem e atuam, na maior parte das vezes, de forma totalmente independente dos cientistas e de suas atividades" (BHASKAR, 1986, p. 3). Além disso, o idealismo e o antirrealismo supostamente praticariam um relativismo ontológico na educação física, pois ambos produzem uma interdição da Verdadeira ontologia: pelo pensamento, no primeiro caso, e pela linguagem, no segundo.

Por fim, se apelar ao vocabulário mestre da ontologia resolvesse supostos problemas que marcam o espírito do tempo da área, tais como os irracionalismos e os antirrealismos presentes na educação física, a contrapartida dessa solução significa um passo contrário na direção do pluralismo teórico e político que tem caracterizado nossa atividade epistemológica nesses últimos anos. Isso se explica por-

8Ávila (2008), na renovação proposta, mantém uma tese implícita/explícita na classificação anterior: a de que é somente no realismo científico, ou seja, na matriz crítico-dialética, que encontraríamos os Fundamentos mais adequados (leia-se, mais Verdadeiros) para o teorizar em educação física. 
que, na medida em que se defende que apenas a ontologia dá o acesso à verdadeira realidade entre nós, desqualifica-se a presença de uma série de outras perspectivas de análise (as representadas, por exemplo, por Deleuze, Foucault, Rorty, Lyotard, Habermas) que, na em direção distinta à dos argumentos ontológicos aqui apresentados, trabalham com a ideia segundo a qual, para citar Gadamer (2007, p. 612), "[...] ser que pode ser compreendido é linguagem". Não vale a pena pagar o preço tão alto ao desqualificar essas perspectivas. Mais profícuo seria realizar estudos bem pontuais da obra dos autores responsáveis pela presença dos giros e analisar se as críticas a eles direcionadas (céticos, irracionalistas, relativistas, conservadores etc.) se sustentam quando cotejadas com outras descrições ${ }^{9}$. Tais estudos nos permitiriam analisar se, de fato, as perspectivas que assumiram os giros impossibilitam alcançar algum grau de objetividade do real ou, ao contrário, se elas pensam a objetividade em outros marcos (ficamos com esta hipótese). Possibilitariam, também, discutir se elas seriam irracionalistas, se pressuporiam uma "ontologia velada" (realismo empírico), se expressariam um conservadorismo político ou se praticariam um relativismo ontológico.

Em síntese, é preciso refletir sobre os usos feitos de Lukács e Bhaskar na pretendida virada ontológica na educação física, pois, do contrário, podemos acabar assumindo teses anacrônicas ou sem sentido quando dirigidas a autores contemporâneos. Um exemplo: é difícil aceitar, como Lukács (1976) anunciou e alguns entre nós acabam reproduzindo, que aquelas perspectivas que abrem mão de alcançar a objetividade nos termos de uma correspondência com o real ou que não operam com um conceito correspondentista de verdade são irracionalistas. Na medida em que esse tipo de associação for aceito sem contestação, adjetivaremos de irracionalistas todos aqueles autores que assumiram, no campo da filosofia, os giros ou

\footnotetext{
${ }^{9} \mathrm{O}$ estudo minucioso desses autores coloca em dúvida, inclusive, a tese de que a virada lingüística provocou uma retração da interpretação ontológica. Se tomarmos o exemplo da perspectiva gadameriana, veremos que sua abordagem da hermenêutica está firmemente ancorada na ontologia compreendida como linguagem (a linguagem revela o ser). Semelhante situação aplicar-se-ia a Foucault, com sua ontologia do presente. Tanto um como outro evitam um tratamento da ontologia que pressupõe, eis a diferença deles em relação à crítica marxista aqui em pauta, um ponto arquimediano de objetividade.
} 
viradas. Isso equivale a dizer que boa parte do trabalho filosófico feito na França, na Alemanha e nos EUA, nesses 30 trinta anos, seria facilmente identificada como irracionalista e, como tal, digna de ser descartada. Por consequência, isso que dizer que aqueles que, em educação física, trabalham a partir da hermenêutica filosófica, com a perspectiva habermasiana ou com a filosofia foucaultiana, são todos eles irracionalistas.

Permanece, portanto, o desafio de se realizar outros estudos mais pontuais das obras de autores como Foucault, Deleuze, Gadamer, Habermas, Lyotard, Nietzsche, entre outros, todos eles responsáveis, de diferentes maneiras, pelos giros que hoje são cada vez mais presentes na educação física. Essa seria, em nossa opinião, uma maneira mais adequada para se compreender a corrente pluralização teórica e política que hoje tem caracterizado a produção do conhecimento e a atividade epistemológica em educação física do País.

From the linguistic turn to the ontological turn
on the epistemological activity in Physical
Education
Abstract: This paper reflexes on the interpretation of
some Marxist tradition on the linguistic turn within the
epistemological activity in Physical Education. It
describes the suggested reaction by that point of view
(ontological inflection) toward a opposing position
against that turning point. It concludes analyzing some
implications of the proposed reaction for the
epistemological activity in physical education.
Keywords: Knowledge. Language. Philosophy.
Linguistic Turn. Ontology. Physical Education.

Del giro linguístico al giro ontológico en la actividad epistemológica en Educación Física

Resumen: El artículo presenta la interpretación de parte de la tradición marxista en Educación Física brasileña respecto el cambio o giro lingüístico en el ámbito de su actividad epistemológica. Hace la descripción de la reacción que se sugiere (inflexión ontológica) dicha tradicción con el objetivo de contraponerse aquella presencia. Concluye con algunas implicaciones de la reacción propuesta para la actividad epistemológica en Educación Física.

Palabras-clave: Conocimiento. Lenguaje. Virada Linguítica. Ontología. Educación Física. 


\section{REFERÊNCIAS}

ÁVILA, A. B.; MULLER, H. V. O.; ORTIGARA, V. Ciência e ontologia: alguns apontamentos para refletir a pesquisa em educação física. In: CONGRESSO BRASILEIRO DE CIÊNCIAS DO ESPORTE/CONGRESSO INTERNACIONAL DE CIÊNCIAS DO ESPORTE, 15. e 2., 2007, Recife. Anais... Recife: CONBRACE, CONICE, 2007.

ÁVILA, A. B.; ORTIGARA, V. Realismo crítico e produção do conhecimento em educação: contribuições de Roy Bhaskar. In: REUNIÃO ANUAL DA SSOCIAÇÃO NACIONAL DE PÓS-GRADUAÇÃO EM EDUCAÇÃO, 28., 2005, Caxambu. Anais... Caxambu: ANPED, 2005.

. Conhecimento, sociedade e educação de professores: crítica consistente ou conservadorismo político? Perspectiva, Florianópolis, v. 25, n. 2, 289-313, jul./dez. 2007a.

Educação, conhecimento e ontologia: uma vindicação a partir de Lukács. In: REUNIÃO ANUAL DA ASSOCIAÇÃO NACIONAL DE PÓS-GRADUAÇÃO, 30. 2007b. Caxambu. Anais... Caxambu: ANPED, 2007b.

ÁVILA, A. B. Pós-graduação em educação física e as tendências na produção do conhecimento: o debate entre realismo e antirrealismo. 2008. Tese (Doutorado em Educação) - Programa de Pós-Graduação em Educação, Universidade Federal de Santa Catarina, Florianópolis, 2008.

BETTI, M. Por uma teoria da prática. Motus Corporis, Rio de Janeiro, v. 3, n. 2, p. 73-127, 1996.

BHASKAR, R. Scientific Realism and Human Emancipation. London: Verso, 1986.

. Philosophy and scientifc realism. Tradução de Rodrigo Leitão e Rodrigo Moerbeck. In: BHASKAR, R. A realist theory of science. Leeds: Books, 1975. p. $11-52$

BRACHT, V. Educação física \& ciência: cenas de um casamento (in)feliz. ljuí: UNIJUÍ, 1999.

DELLA FONTE, S. S. As fontes heideggerianas do pensamento pós-moderno. 2006. 233 f. Tese (Doutorado em Educação) - Programa de Pós-Graduação em Educação, Universidade Federal de Santa Catarina, Florianópolis, 2006.

DUAYER, M. Antirrealismo e absolutas crenças relativas. Margem Esquerda, São Paulo, v. 8, p. 109-130, 2006.

FENSTERSEIFER, P. A educação física na crise da modernidade. ljuí: Unijuí, 2001.

Atividade epistemológica e educação física. In: NÓBREGA, T. P. (Org.). Epistemologia, saberes e práticas da educação física. João Pessoa: Editora Universitária/UFPB, 2006, p. 29-37. 
. Educação física e atividade epistemológica: entre o dogmatismo e o relativismo. In: CONGRESSO BRASILEIRO DE CIÊNCIAS DO ESPORTE/CONGRESSO INTERNACIONALDE CIÊNCIAS DO ESPORTE, 16. e 3., 2009, Salvador. Anais... Salvador: CONBRACE, CONICE, 2009.

GADAMER, H. G. Verdade e método I: traços fundamentais de uma hermenêutica filosófica. Rio de Janeiro; Bragança Paulista: Vozes, Editora Universitária São Francisco, 2007.

GAMBOA, S. Teoria e prática: uma relação dinâmica e contraditória. Motrivivência, Florianópolis, n. 08, p. 31-45, 1995.

Reações ao giro lingüístico: o "giro ontológico" ou o resgate do real independente da consciência e da linguagem. In: CONGRESSO BRASILEIRO DE CIÊNCIAS DO ESPORTE/CONGRESSO INTERNACIONAL DE CIÊNCIAS DOESPORTE, 15. e 2., 2007, Recife. Anais... Recife: CONBRACE, CONICE, 2007.

HOSTINS, R. C. L. Formação de pesquisadores na Pós-Graduação em Educação: embates epistemológicos, dimensões ontológicas. 2006. 233 f. Tese (Doutorado em Educação) - Programa de Pós-Graduação em Educação, Universidade Federal de Santa Catarina, Florianópolis, 2006.

LIMA, H. L. Pensamento epistemológico da educação física brasileira: das controvérsias acerca do estatuto científico. 1999. Dissertação (Mestrado em Educação) - Universidade Federal de Pernambuco, Recife, 1999.

LOVISOLO, H. R. Educação física: arte da mediação. Rio de Janeiro: Sprint, 1995. v. 1.

LUKÁCS, G. El Assalto a la razón: la trayectoria del irracionalismo desde Schelling hasta Hitler. Barcelona: Grijalbo, 1976.

A autocrítica do marxismo. Temas de Ciências Humanas, São Paulo, n. 9, p. 19-25, 1978.

MORAES, M. C. M. O renovado conservadorismo da agenda pós-moderna. Cadernos de Pesquisa, Campinas, v. 34, n. 122, p 337-357, maio/ago. 2004.

ORTIGARA, V. Ausência sentida nos estudos em educação física: a determinação ontológica do ser social. 2002. Tese (Doutorado em Educação) - Programa de Pós-Graduação em Educação, Universidade Federal de Santa Catarina, Florianópolis, 2002.

ORTIGARA, V. et al. Apontamentos sobre formação humana e educação na produção de conhecimento em educação física. In: CONGRESSO BRASILEIRO DE CIÊNCIAS DOESPORTE/CONGRESSO INTERNACIONAL DE CIÊNCIASDO ESPORTE, 16. e 3., 2000, Salvador. Anais... Salvador: CONBRACE, CONICE, 2009.

RORTY, R. A filosofia e o espelho da natureza. Rio de Janeiro: Relume-Dumará, 1994. 
Do giro linguístico ao giro ontológico na atividade epistemológica...

Ensaios sobre Heidegger e outros escritos filosóficos. Rio de Janeiro: Relume-Dumará, 1999.

. Uma visão pragmatista da filosofia analítica contemporânea. In: RORTY, R.; GHIRALDELLI JÚNIOR, P. Ensaios pragmatistas: entre subjetividade e verdade. Rio de Janeiro: DP\&A, 2006. p. 105-125.

SOUZA E SILVA, R. V. Mestrados em educação física no Brasil: pesquisando suas pesquisas. 1990. Dissertação (Mestrado em Ciência do Movimento Humano). Programa de Pós-Graduação em Ciência do Movimento Humano da Universidade Federal de Santa Maria, Santa Maria, 1990.

WOOD, E. O que é a agenda "pós-moderna"? In: WOOD, E.; FOSTER, J. B. (Org.). Em defesa da história: marxismo e pós-modernismo. Rio de Janeiro: Jorge Zahar, 1999. p. 7-22.

A pesquisa contou com apoio do CNPq (Auxílio pesquisa, bolsas de produtividade em pesquisa, doutorado, mestrado, apoio técnico à pesquisa, iniciação científica).

Recebido em: 18.03.2010

Aprovado em: 16.04. 2010

Movimento, Porto Alegre, v. 16, n. 03 p. 11-29, julho/setembro de 2010. 